\title{
Youth Depression Alleviation: Augmentation with an anti-inflammatory agent (YoDA-A): Protocol and rationale for a placebo-controlled randomised trial of rosuvastatin and aspirin
}

\section{$\underline{\text { Abstract }}$}

Aim: There is growing support for the role of inflammation and oxidative stress in the pathophysiology of Major Depressive Disorder. This has led to the development of novel strategies targeting inflammation in the treatment of depression. Rosuvastatin and aspirin have well-documented anti-inflammatory and antioxidant properties. The aim of the Youth Depression Alleviation: Augmentation with an antiinflammatory agent (YoDA-A) study is to determine whether individuals receiving adjunctive anti-inflammatory agents, aspirin and rosuvastatin, experience a reduction in the severity of MDD compared with individuals receiving placebo.

Methods: YoDA-A is a 12-week triple-blind, randomised controlled trial, funded by the National Health and Medical Research Council, Australia. Participants aged 1525, with moderate-to-severe Major Depressive Disorder, are allocated to receive either $10 \mathrm{mg} /$ day rosuvastatin, $100 \mathrm{mg} /$ day aspirin, or placebo, in addition to treatment as usual. Participants are assessed at baseline and at weeks 4, 8, 12, and 26. The primary outcome is change in the Montgomery-Åsberg Depression Rating Scale (MADRS) from baseline to week 12.

Results: The study is planned to be completed in 2017. At date of publication, 75 participants have been recruited. 
Discussion: Timely and targeted intervention for youth MDD is crucial. Given the paucity of new agents to treat youth MDD, adjunctive trials are not only pragmatic and 'real-world', but additionally aim to target shortfalls in conventional medications. This study has the potential to first provide two new adjunctive treatment options for youth MDD; aspirin and rosuvastatin. Second, this study will serve as proof of principle of the role of inflammation in MDD.

Keywords: aspirin, depression, inflammation, rosuvastatin, youth.

Trial registration: Australian New Zealand Clinical Trials Registry: ACTRN12613000112763 


\section{Introduction}

Depression is the most prevalent health problem in young people, with up to $24 \%$ experiencing major depressive disorder (MDD) before they reach the age of $25 .{ }^{1}$ These rates may be increasing. ${ }^{2}$ MDD in youth is of particular concern, not only due to the social and developmental impact of the disease $\mathrm{e}^{3,4}$ but also because depression during this period may lead to multiple recurrent major depressive episodes. ${ }^{5,6}$

Depression theory and treatment options have focused on the monoamine hypothesis, postulating that depression is the result of a deficiency of certain monoamine neurotransmitters. ${ }^{7}$ While monoamines play a role in the pathophysiology of depression, this approach has neither delivered effective treatments for many individuals, or produced novel agents, beyond the limited treatment options currently available. ${ }^{8,9}$ Current conceptualisation of the neurobiology of depression has shifted from monoamines, incorporating changes in inflammatory and oxidative stress into a more comprehensive model of illness neuroprogression. ${ }^{10}$

There are data demonstrating that stress and depression are associated with increased immune activation, impaired immune function, and inflammation. ${ }^{11,12}$ Adolescent depression is associated with an inflammatory response, particularly marked in suicidal individuals. ${ }^{13}$ Elevated levels of C-reactive protein (a marker of inflammation; CRP) predict the later onset of depression, suggesting that the immune findings are not mere epiphenomena of depression, but contribute to the genesis of the disorder. ${ }^{14}$ Some antidepressant treatments reduce inflammatory marker levels in MDD patients ${ }^{15,16}$ and reduce the release of inflammatory factors 
from stimulated microglia. ${ }^{17,18}$ A lack of treatment response to traditional antidepressants is associated with elevated inflammatory marker levels ${ }^{19,20}$, suggesting an immunomodulatory role for successful use of antidepressant medication and opening the door to interventions that directly target the pathophysiology of depression.

The relationship between oxidative stress and depression is also supported. Compared with healthy controls, individuals experiencing a Major Depressive Episode have significantly elevated markers of oxidative damage ${ }^{21}$, whilst another study demonstrated that oxidative stress was significantly higher in medication-free patients with MDD than in controls. ${ }^{22}$ Positive correlations have been shown between oxidative stress index values and depressive severity scores. ${ }^{22-26}$ Oxidative parameters return to normal with the resolution of depressive symptoms after selective serotonin re-uptake inhibitor (SSRI) treatment, supporting the contention that oxidative stress has an intrinsic role in the disease process. ${ }^{23,27}$

There is currently minimal evidence to support the effectiveness of any nonpsychotherapeutic treatment for depression in young people, with the exception of fluoxetine. ${ }^{28,29}$ Although effective, fluoxetine carries an increased risk of suicidal ideation in those aged under $25^{30-33}$, as well as the risk of other side effects that may affect quality of life. There is, therefore, a clear need for the development of interventions with demonstrated effectiveness, which are acceptable to young people experiencing MDD. Statins (3-hydroxy-3-methylglutaryl coenzyme A reductase inhibitors), such as rosuvastatin, have well-documented anti-inflammatory 
and antioxidant properties, as do aspirin and other non-steroidal anti-inflammatory drugs (NSAID). ${ }^{34,35}$

In vivo statin treatment has been demonstrated to reduce oxidative stress. ${ }^{36-}$ 39 Rosuvastatin has been shown to reduce markers of oxidative stress and inflammation in animal studies ${ }^{34}$ and in patients with hypertension and dyslipidaemia. ${ }^{35}$ In an adult sample, it has been found that lovastatin, when used as adjunctive treatment, is effective for treating patients with MDD. ${ }^{40}$ Both rosuvastatin and lovastatin belong to the class of statins, although the former is hydrophilic and the later lipophilic . Based on its action in reducing oxidative stress and the links with depressive symptoms, rosuvastatin may therefore be useful in reducing symptoms.

Adults with first-episode depression who received aspirin together with fluoxetine had a greater reduction of oxidative stress parameters than those who received fluoxetine monotherapy..$^{41}$ In schizophrenia, a recent study has shown that aspirin reduces core symptoms of the disorder, with a significant decrease in total and positive symptoms. ${ }^{42}$ Given the biological similarities between mood and psychotic disorders, this is an intriguing lead.

The above evidence supports a possible role of oxidative and inflammatory processes in depression. It argues for the evaluation of rational and novel pathophysiologically-based therapies that are distinct from conventional antidepressants. 


\section{Method}

\section{Study Design}

The study design is a 12-week, parallel group, triple-blind, randomised-control trial in participants with moderate to severe MDD, allocated to receive either rosuvastatin, or aspirin, or placebo, in addition to treatment as usual (TAU). Assessments are completed at baseline and weeks 4,8 and 12, with a telephone follow-up assessment at week 26 to determine post-discontinuation effects. Blood samples are collected at baseline and week 12 for the investigation of inflammatory and oxidative stress markers. The most relevant markers, based on current literature at the end of the study, will be explored. The study was approved by the Melbourne Health Human Research Ethics Committee (\#HREC/12/MH/148). The study was funded by the National Health and Medical Research Council of Australia and sponsored by Orygen, the National Centre of Excellence in Youth Mental Health, without limitations on publication.

The primary hypothesis is that after 12 weeks of treatment, both the rosuvastatin and aspirin treatment groups will show greater improvement from baseline than the placebo group, on the Montgomery-Åsberg Depression Rating Scale (MADRS). ${ }^{43}$

The secondary hypotheses are that the rosuvastatin and aspirin treatment groups will show greater improvement compared to the placebo group on measures of clinical global status, functioning, quality of life, and symptomatology from baseline to week 12; that these effects, and the reduction in MADRS will be seen at the week 26 follow-up in the rosuvastatin and aspirin groups, compared with placebo; and 
that those in the active arms will have reduced levels of inflammatory and oxidative stress levels in serum; and that oxidative stress and inflammation will mediate clinical change.

Tertiary analyses will also be completed to explore mediating factors in the response to rosuvastatin and aspirin treatment.

\section{Study setting}

The study is being conducted at the Youth Mood Clinic at Orygen Youth Health, Jigsaw - Barwon Health, and in headspace centres in Geelong and Melbourne, Australia.

TAU at these sites includes case management, cognitive behavioural therapy, and pharmacotherapy.

The study commenced recruitment in June 2013 at OYH and headspace centres at Glenroy and Sunshine, Victoria. Recruitment at Barwon Health site and Geelong headspace will commence in coming months. The study has recruited 75 participants to date and of those, 49 have completed week 12 and 30 have completed week 26. 


\section{Inclusion and Exclusion Criteria}

To be included in the study participants must: (i) be aged between 15 and 25 years; (ii) have a diagnosis of current MDD using the Structured Clinical Interview for DSM-IV Axis I Disorders, patient version $\left(\right.$ SCID-I/P) ${ }^{44}$; (iii) have a score on the $\mathrm{MADRS}^{43}$ of 20 or greater, indicating moderate to severe depression; (iv) have the ability to give informed consent and to comply with standard procedures; (v) use effective contraception if female and sexually active with members of the opposite sex; (vi) have fluency in English; and (vii) have stable pharmacological treatment for at least two weeks prior to enrolment (any changes in medication dose or frequency of therapy is excepted), if currently being treated.

Exclusion criteria are: (i) lifetime or current SCID-I/P diagnosis of a psychotic disorder; (ii) a lifetime SCID-I/P diagnosis of bipolar I or II disorder or alcohol dependence; (iii) an acute or unstable systemic medical disorder; (iv) an inability to comply with the requirements of informed consent or the study protocol; (v) a history of intolerance or allergy to study medications; (vi) those who are currently pregnant or breast feeding (vii) the current regular use of statins, aspirin, NSAID's paracetamol, corticosteroids or any other immunomodulatory agents; (viii) the current or recent use of hypolipidaemics, vitamin $\mathrm{K}$ antagonists and other anticoagulants, protease inhibitors, ketoconazole, spironolactone; or cimetidine.

\section{Discontinuation and withdrawal}

Discontinuation of a participant occurs at the discretion of the participant, researcher, or treating physician. Automatic discontinuation occurs if a participant developments a psychotic disorder, bipolar disorder, is pregnant or at risk of 
pregnancy, or if they commence rosuvastatin or aspirin treatment. Due to the increased risk of myopathy with rosuvastatin and concurrent heavy alcohol use, a score $>20$ on the Alcohol Use Disorders Identification Test (AUDIT) ${ }^{45}$ necessitates review by the treating physician, and potential discontinuation. Due to the increased risk of bleeding with aspirin, any surgery planned by the participant requires review by the treating physician. Upon discontinuation, the participant is offered the opportunity to continue to contribute to data collection at the follow-up time points.

\section{Interventions}

Participants receive either $10 \mathrm{mg} /$ day rosuvastatin; or $100 \mathrm{mg} /$ day aspirin; or placebo, in addition to TAU. At each visit, participants are requested to return all unused investigational products. Adherence to medication is assessed by a pill count.

The doses of rosuvastatin and aspirin are derived from the literature regarding the doses at which their targeted actions are effective and the safety profile of each agent. With these factors in mind, $10 \mathrm{mg}$ of rosuvastatin reflects the lowest prescribed therapeutic dose. ${ }^{46}$ The $100 \mathrm{mg}$ dose of aspirin is the same dose used to prevent cardiac events and has been shown to have anti-inflammatory properties. ${ }^{46}$ Blinding is maintained by ensuring that the packaging, and appearance of rosuvastatin, aspirin and placebo capsules are identical. All tablets were overcapsulated for blinding purposes, to appear and taste identical.

\section{Outcome measures}

The primary outcome measure is the MADRS. ${ }^{43}$ The following measures are used to assess effectiveness: change in MADRS; change in the Quick Inventory of 
Depression Symptomatology-Self Report (QIDS-SR) ${ }^{47}$; change of rates of remission (defined as MADRS $\leq 7$ ); changes in the Generalized Anxiety Disorder 7-item scale $(G A D-7)^{48}$ scores; response, defined as the Clinical Global Impression-Severity scale and the Clinical Global Impression-Improvement scale ${ }^{49}$; and change in self-rated depressive symptoms, assessed using the Patient Global Impression Improvement $(P G I)^{50}$. Quality of life is assessed using the Quality of life Enjoyment and Satisfaction Questionnaire - Short Form (Q-LES-Q-SF) ${ }^{51}$ and the Social Adjustment Scale - Self Report (SAS-SR) $)^{52}$; The Social and Occupational Functioning Scale (SOFAS) ${ }^{53}$ is used to measure psychosocial (social and occupational) functioning.

\section{Predictors, moderators and mediators of treatment response}

Potential predictors and moderators of treatment response are assessed using the Dimensional Assessment of Personality Pathology Basic Questionnaire $(D A P P)^{54}$, the SCID-I/P substance use module ${ }^{44}$, the AUDIT $^{45}$ and the Negative Problem Orientation Questionnaire (NPOQ) $)^{55}$. Although participants with syndromal bipolar disorder (BD) are excluded from the study, subthreshold bipolar symptoms are characterised in an index which includes the Bipolar Spectrum Diagnostic Scale BSDS $^{56}$ and the Young Mania Rating Scale YMRS $^{57}$. Full details of the index and outcomes will be published as a separate sub-study.

Peripheral markers of inflammation and oxidative stress will be explored in consenting participants (blood sampling is optional). Serum, plasma and whole blood are collected from $30 \mathrm{ml}$ of blood, taken at baseline and week 12 . Samples are stored at -80 degrees Celsius until analysis. 
Participants may also optionally consent to baseline brain imaging. These data will be analysed to determine whether brain imaging variables predicts treatment outcome. As this is a sub-study of the main trial, details of this protocol will be published elsewhere.

\section{Safety and adverse events}

The trial is monitored by an independent Data and Safety Monitoring Committee (DSMC). Adverse events (AEs) are collected from the time that informed consent has been obtained until the end of the week 12 intervention period using open questions. After the 12-week intervention period AEs are followed up until the AE is resolved or until 7 days after trial medication has ceased. All Serious Adverse Events are reported to all relevant regulatory authorities.

Suicidal thinking is assessed with the Suicidal Ideation Questionnaire (SIQ) ${ }^{58}$ and suicidality is assessed with the Columbia Suicide Severity Rating Scale C-SSRS. ${ }^{59}$ If a participant scores 5 on intensity of suicidal ideation in the past month, the participant's continuation in the study is reviewed. If a participant scores 20 or above on the AUDIT at any trial visit, their treating physician is informed and the participant is reviewed.

At baseline and week 12, specific blood tests are performed for safety purposes. At baseline, these comprise: a full blood examination, liver function tests (LFT), urea and electrolytes (U\&E), C-Reactive protein random glucose, vitamin B12 and folate, creatinine kinase (CK), and thyroid stimulating hormone. At week 12 , the LFT, U\&E and CK are repeated.

\section{Procedure}


Written informed consent is obtained by the investigator or research assistant. If a participant is $<18$ years, consent is obtained from both the parent/legal guardian and the participant. If eligibility is confirmed the baseline assessment is conducted (see Figure 1 for participant flow chart). The participant is randomised to the rosuvastatin, aspirin, or placebo groups. Investigators, clinicians, research assistants, and statisticians are blind to treatment allocation for data collection and analysis.

Following baseline assessment and randomisation, participants are subsequently assessed at weeks 4,8 and 12 on psychopathology, functioning, adverse events and side effects. Instruments and procedures implemented at each study visit are outlined in Table 1. A follow up assessment is also conducted over the telephone at week 26. For engagement and safety purposes, the participant is also telephoned at week 2. Formal inter-rater reliability assessments are carried out at various stages throughout the study.

Participants are reviewed by a treating doctor at baseline, and are seen again one week after commencing medication. The doctor then reviews the participant at weeks 4,8 , and 12 .

\section{$\underline{\text { Randomisation }}$}

Participants are randomised to the three groups in a 1:1:1 ratio. Randomisation is enabled by computer-generated numbers programmed into the electronic case report form (eCRF) and conducted according to the International Conference on Harmonisation (ICH) Guideline. The randomisation is stratified by 
gender and age ( $<18$ vs. $\geq 18$ years) and participants are allocated to treatment groups using randomly permuted blocks of varying size within each stratum.

Online unblinding is available for emergency situations. If unblinded, participants discontinue treatment in the study but continue to be assessed at the scheduled times, provided they have not withdrawn consent.

\section{Statistical analyses}

Primary analyses will be undertaken on an intent-to-treat basis, including all participants as randomised, regardless of treatment actually received or withdrawal from the study. Mixed-model repeated measures (MMRM) analyses will be used to analyse change in the primary outcome measure (MADRS). ${ }^{60} A$ priori planned comparisons of change from baseline to the week 12 endpoint will be used to test the primary hypotheses. The most suitable, parsimonious variance-covariance structure for the relationships between observations at different occasions will be determined using information measures. Stratification variables and other variables found to be substantially imbalanced between groups post randomisation will be tentatively included in these models and retain if statistically significant and influential on outcomes. Similar analyses of scaled secondary measures will assess differential change on clinical global status, symptom burden, quality of life and functioning. Mathematical transformation or categorisation of raw scores may be undertaken to meet distributional assumptions and include outliers. For dichotomous outcomes such as remission, a comparable mixed modelling approach will be used. Relative and reduction in risk of remission based on MADRS score 
status will be estimated at the trial endpoint and follow-up. Number needed to treat ${ }^{61}$ will be derived from these values.

In addition to ITT estimates of the effectiveness of each treatment, alternative estimates of effects will be calculated using subgroups identified as having complied with treatment schedules to an extent judged necessary to induce clinical change. Complier, per protocol and complier average causal effect ${ }^{62}$ estimates may be examined.

The differential effectiveness of aspirin and rosuvastatin will be examined on outcome variables. As differences between the two active treatments are likely to be small, it is acknowledged that these analyses are exploratory. Safety data will be compared between treatment arms using Fisher's exact test. All tests of treatment effects will be conducted using a two-sided alpha level of 0.05 and $95 \%$ confidence intervals. Changes in biological markers will be explored between baseline and endpoint and the role of oxidative stress and inflammatory markers as potential mediators of depressive symptom outcome will be investigated using structural equation models. ${ }^{63}$

\section{Determination of sample size}

Based on previous work ${ }^{42}$ we estimate baseline-endpoint effect sizes for the aspirin treatment to be between 0.26 and 0.47 standard deviations. Larger effect sizes for statins have been observed in epidemiological studies, with data indicating a $79 \%$ reduction in risk of developing depression. ${ }^{64}$ An effect size of this magnitude is unlikely to be observed in a treatment study. Power calculations for the primary 
outcome were conservatively based on those smaller estimated effect sizes for aspirin. To sufficiently power the study ( $80 \%$ power) to detect differences in change from baseline of approximately 0.4 standard deviations in a priori contrasts of treatment arms conducted within the framework of omnibus test of condition-bytime mixed model repeated measures (MMRM) analysis, and assuming a correlation of 0.5 between baseline and endpoint measurements, a total sample size of 200 is required. A sample of 270 is therefore proposed, allowing attrition rates up to $25 \%$.

\section{Data management}

Data collection and entry is conducted according to GCP guidelines. ${ }^{65,66}$ Monitoring of the data is conducted by the DSMC, the Project Manager and the Sponsor-appointed Clinical Research Associate.

\section{Discussion}

Despite the high burden of youth depression, there is limited evidence supporting current pharmacological and psychosocial treatments in this area, leading to a call for new treatments to be developed. The current trial aims to investigate the effectiveness of add-on doses of aspirin or rosuvastatin in the treatment of youth depression.

If the study shows effectiveness in either of the two treatment arms, a novel approach to treating youth depression will be supported. Additionally, should the study demonstrate positive findings, targeted treatments might be further developed by linking the positive results seen in clinical symptoms with biological markers. This study will additionally provide information regarding the biological 
underpinnings of youth depression. As samples are taken at baseline and at the end of the treatment phase, this allows us to explore the pathophysiology of depression in this cohort.

Apart from the effect of individual treatment arms, participant characteristics might moderate or mediate treatment response. Smoking, for example, has a differential effect on anti-oxidant systems such as paraoxonases among persons with bipolar and unipolar affective disorders ${ }^{67}$, indicating a variable impact of antiinflammatory agents. Personality factors have been associated with both poor outcome among depressed persons. $^{68}$ Diagnostic conversion from MDD to BD can also be examined within this study, in the 6-month prospective follow up of participants included in the trial. Given the association between lower age of onset of $\mathrm{MDD}$ and higher risk of conversion to $\mathrm{BD}^{69-71}$ the rate of conversion to $\mathrm{BD}$ may be moderate to high.

This study will explore the effectiveness of aspirin and rosuvastatin as novel therapies and provide meaningful data related to youth depression and the trajectory of illness in this cohort. 


\section{$\underline{\text { References }}$}

1. Lewinsohn PM, Rohde P, Seeley JR. Major depressive disorder in older adolescents: prevalence, risk factors, and clinical implications. Clin Psychol Rev. 1998; 18(7): 765-94.

2. Twenge JM, Gentile B, DeWall CN, Ma D, Lacefield K, Schurtz DR. Birth cohort increases in psychopathology among young Americans, 1938-2007: A cross-temporal meta-analysis of the MMPI. Clin Psychol Rev. 2010; 30(2): 145-54.

3. Weissman MM, Wolk S, Goldstein RB, Moreau D, Adams P, Greenwald S, et al. Depressed adolescents grown up. Journal of the American Medical Association. 1999; 281(18): 1707-13.

4. Fergusson DM, Woodward LJ. Mental health, educational, and social role outcomes of adolescents with depression. Arch Gen Psychiatry. 2002; 59: 225-31.

5. Birmaher B, Williamson DE, Dahl RE, Axelson DA, Kaufman J, Dorn LD, et al. Clinical presentation and course of depression in youth: Does onset in childhood differ from onset in adolescence? Journal of the American Academy of Child and Adolescent Psychiatry. 2004; 43(1): 64-70.

6. Fombonne E, Wostear G, Cooper V, Harrington R, Rutter M. The Maudsley long-term follow-up of child and adolescent depression: 1. Psychiatric outcomes in adulthood. British Journal of Psychiatry. 2001; 179: 210-7.

7. Hirschfield RMA. History and evolution of the monoamine hypothesis of depression. Journal of Clinical Psychiatry. 2000; 61(Supplement 6): 4-6. 
8. Haase J, Brown E. Integrating the monoamine, neurotrophin and cytokine hypotheses of depression - a central role for the serotonin transporter? Pharmacology and Therapeutics. 2015; 147: 1-11.

9. Trivedi M, Rush AJ, Wisniewski AA, Nierenberg D, Warden L, Ritz L, et al. Evaluation of outcomes with citalopram for depression using measurement-based care in STAR*D: Implications for clinical practice. Am J Psychiatry. 2006; 163: 28-40.

10. Berk M, Kapczinski F, Andreazza AC, Dean OM, Giorlando F, Maes M, et al. Pathways underlying neuroprogression in bipolar disorder: Focus on inflammation, oxidative stress and neurotrophic factors. Neurosci Biobehav Rev. 2011; 35(3): 80417.

11. Breese CR, Freedman R, Leonard SS. Glutamate receptor subtype expression in human postmortem brain tissue from schizophrenics and alcohol abusers. Brain Research. 1995; 674(1): 82-90.

12. Valkanova V, Ebmeier KP, Allan CL. CRP, IL-6 and depression: a systematic review and meta-analysis of longitudinal studies. Journal of Affective Disorders. 2013; 150: 736-44.

13. Gabbay V, Klein RG, Guttman LE, Babb JS, Alonso CM, Nishawala M, et al. A preliminary study of cytokines in suicidal and nonsuicidal adolescents with major depression. J Child Adolesc Psychopharmacol. 2009; 19(4): 423-30.

14. Pasco JA, Nicholson GC, Williams L, Jacka FN, Henry MJ, Kotowicz MA, et al. Association of high-sensitivity C-reactive protein with de novo major depression. $\mathrm{Br} \mathrm{J}$ Psychiatry. 2010; 197: 372-7.

15. Kalivas PW, O'Brien C. Drug addiction as a pathology of staged neuroplasticity. Neuropsychopharmacology. 2008; 33(1): 166-80. 
16. Basterzi AD, Aydemir C, Kisa C, Aksaray S, Tuzer V, Yazici K, et al. IL-6 levels decrease with SSRI treatment in patients with major depression. Hum Psychopharmacol. 2005; 20(7): 473-6.

17. Tynan RJ, Weidenhofer J, Hinwood M, Cairns MJ, Day TA, Walker FR. A comparative examination of the anti-inflammatory effects of SSRI and SNRI antidepressants on LPS stimulated microglia. Brain, Behavior, and Immunity. 2012; 26(3): 469-79.

18. Dhami KS, Churchward MA, Baker GB, Todd KG. Fluoxetine and citalopram decrease microglial release of glutamate and d-serine to promote cortical neuronal viability following ischemic insult. Molecular and Cellular Neuroscience. 2013; 56: 365-74.

19. Eller T, Vasar V, Shlik J, Maron E. Pro-inflammatory cytokines and treatment response to escitalopram in major depressive disorder. Prog Neuropsychopharmacol Biol Psychiatry. 2008; 32(2): 445-50.

20. O'Brien SM, Scully P, Fitzgerald P, Scott LV, Dinan TG. Plasma cytokine profiles in depressed patients who fail to respond to selective serotonin reuptake inhibitor therapy. J Psychiatr Res. 2007; 41: 326-31.

21. Ng F, Berk M, Dean O, Bush Al. Oxidative stress in psychiatric disorders: evidence base and therapeutic implications. Int J Neuropsychopharmacol. 2008; 11(6): 851-76.

22. Yanik M, Erel O, Kati M. The relationship between potency of oxidative stress and severity of depression. Acta Neuropsychiatrica. 2004; 16: 200-3. 
23. Bilici M, Efe H, Koroglu MA, Uydu HA, Bekaroglu M, Deger O. Antioxidative enzyme activities and lipid peroxidation in major depression: alterations by antidepressant treatments. J Affect Disord. 2001; 64(1): 43-51.

24. Sarandol A, Sarandol E, Eker SS, Erdinc S, Vatansever E, Kirli S. Major depressive disorder is accompanied with oxidative stress: short-term antidepressant treatment does not alter oxidative-antioxidative systems. Hum Psychopharmacol. 2007; 22(2): 67-73.

25. Forlenza MJ, Miller GE. Increased serum levels of 8-hydroxy-2'deoxyguanosine in clinical depression. Psychosom Med. 2006; 68(1): 1-7.

26. Owen AJ, Batterham MJ, Probst YC, Grenyer BF, Tapsell LC. Low plasma vitamin E levels in major depression: diet or disease? Eur J Clin Nutr. 2005; 59(2): 304-6.

27. Khanzode SD, Dakhale GN, Khanzode SS, Saoji A, Palasodkar R. Oxidative damage and major depression: the potential antioxidant action of selective serotonin re-uptake inhibitors. Redox Rep. 2003; 8(6): 365-70.

28. Homsi S, Federico F, Croci N, Palmier B, Plotkine M, Marchand-Leroux C, et al. Minocycline effects on cerebral edema: relations with inflammatory and oxidative stress markers following traumatic brain injury in mice. Brain Research. 2009; 1291 : $122-32$.

29. Whittington CJ, Kendall T, Fonagy P, Cottrell D, Cotgrove A, Boddington E. Selective serotonin reuptake inhibitors in childhood depression: systematic review of published versus unpublished data. Lancet. 2004; 363: 1341-5.

30. Laughren T. Memorandum: overview for the December 13 meeting of Psychopharmacologic Drugs Advisory Committee. 2006. 
31. Hetrick SE, McKenzie JE, Cox GR, Simmons MB, Merry SN. Newer generation antidepressants for depressive disorders in children and adolescents. Cochrane Database Syst Rev 2012; 11(CD004851).

32. US Food and Drug Administration. Relationship between psychotropic drugs and pediatric suicidality: review and evaluation of clinical data. 2004.

33. ADRAC. Use of SSRI antidepressants in children and adolescents. 2004.

34. Sicard P, Delemasure S, Korandji C, Segueira-Le Grand A, Lauzier B, Guilland JC, et al. Anti-hypertensive effects of Rosuvastatin are associated with decreased inflammation and oxidative stress markers in hypertensive rats. Free Radic Res. $2008 ; 42(3): 226-36$.

35. Gomez-Garcia A, Martinez Torres G, Ortega-Pierres LE, Rodriguez-Ayala E, Alvarez-Aguilar C. [Rosuvastatin and metformin decrease inflammation and oxidative stress in patients with hypertension and dyslipidemia]. Rev Esp Cardiol. 2007; 60(12): 1242-9.

36. Schupp N, Schmid U, Heidland A, Stopper H. Rosuvastatin protects against oxidative stress and DNA damage in vitro via upregulation of glutathione synthesis. Atherosclerosis. 2008; 199(2): 278-87.

37. Holvoet P. Relations between metabolic syndrome, oxidative stress and inflammation and cardiovascular disease. Verh K Acad Geneeskd Belg. 2008; 70(3): 193-219.

38. Habibi J, Whaley-Connell A, Qazi MA, Hayden MR, Cooper SA, Tramontano A, et al. Rosuvastatin, a 3-hydroxy-3-methylglutaryl coenzyme a reductase inhibitor, decreases cardiac oxidative stress and remodeling in Ren2 transgenic rats. Endocrinology. 2007; 148(5): 2181-8. 
39. Ajith TA, Riji T, Anu V. In vitro anti-oxidant and DNA protective effects of the novel 3-hydroxy-3-methylglutaryl coenzyme A reductase inhibitor rosuvastatin. Clin Exp Pharmacol Physiol. 2008; 35(5-6): 625-9.

40. Ghanizadeh A, Hedayati A. Augmentation of fluoxetine with lovastatin for treating major depressive disorder, a randomized double-blind placebo controlledclinical trial. Depression and Anxiety. 2013; 30: 1084-8.

41. Galecki P, Szemraj J, Bienkiewicz M, Zboralski K, Galecka E. Oxidative stress parameters after combined fluoxetine and acetylsalicylic acid therapy in depressive patients. Hum Psychopharmacol. 2009; 24(4): 277-86.

42. Laan W, Grobbee DE, Selten JP, Heijnen CJ, Kahn RS, Burger H. Adjuvant aspirin therapy reduces symptoms of schizophrenia spectrum disorders: results from a randomized, double-blind, placebo-controlled trial. J Clin Psychiatry 2010; 71(5): 520-7.

43. Montgomery SA, Asberg M. A new depression scale designed to be sensitive to change. Br J Psychiatry. 1979; 134: 382-9.

44. First MB, Spitzer RL, Gibbon M, Williams JBW. Structured Clinical Interview for DSM-IV Axis I Disorders (SCID-I), 1997.

45. Babor TF, Higgins-Biddle JC, Saunders JB, Monteiro MG. The Alcohol Use Disorders Identification Test (AUDIT): Guidelines for use in primary care. World Health Organization, 2001.

46. Australian Medicines Handbook. Australian Medicines Handbook. Adelaide: Australian Medicines Handbook Pty Ltd; 2015 [cited 2015 Apr 4]. Available from: Australian Medicines Handbook Online. 
47. Rush AJ, Trivedi MH, Ibrahim HM, Carmody TJ, Arnow B, Klein DN, et al. The 16-Item Quick Inventory of Depressive Symptomatology (QIDS), clinician rating (QIDS-C), and self-report (QIDS-SR): a psychometric evaluation in patients with chronic major depression. Biol Psychiatry. 2003; 54: 573-83.

48. Spitzer RL, Kroenke K, Williams JBW, Lowe B. A brief measure for assessing Generalized Anxiety Disorder. Arch Intern Med. 2006;166:1092-7.

49. Guy W, ed. Clinical Global Impressions (CGI): ECDEU assessment manual for psychophamacology. Rockville, MD: US Department of Heath, Education, and Welfare Public Health Service Alcohol, Drug Abuse, and Mental Health Administration, 1976.

50. Yalcin I, Bump RC. Validation of two global impression questionnaires for incontinence. Am J Obstet Gynecol. 2003; 189: 98-101.

51. Endicott J, Nee J, Harrison W, Blumenthal R. Quality of Life Enjoyment and Satisfaction Questionnaire: a new measure. Psychopharmacol Bull. 1993; 29: 321-6.

52. Weissman MM, Prusoff BA, Thompson WD, Harding PS, Myers JK. Social adjustment by self-report in a community sample and in psychiatric outpatients. J Nerv Ment Dis. 1978; 166: 317-26.

53. Morosini PL, Magliano L, Brambilla L, Ugolini S, Pioli R. Development, reliability and acceptability of a new version of the DSM-IV Social and Occupational Functioning Assessment Scale (SOFAS) to assess routine social functioning. Acta Psychiatr Scand. 2000; 101: 323-9.

54. Livesley WJ, Jackson DN. Dimensional Assessment of Personality Pathology Basic Questionnaire. Port Huron: SIGMA Assessment Systems, 2009. 
55. Robichaud M, Dugas MJ. Negative problem orientation (Part I): psychometric properties of a new measure. Behaviour Research and Therapy 2004 43: 391-401.

56. Ghaemi SN, Miller CJ, Berv DA, Klugman J, Rosenquist KJ, Pies RW. Sensitivity and specificity of a new bipolar spectrum diagnostic scale. Journal of Affective Disorders 2005; 84(2-3): 273-7.

57. Young RC, Biggs JT, Ziegler VE, Meyer DA. A rating scale for mania: reliability, validity and sensitivity. The British Journal of Psychiatry 1978; 133(5): 429-35.

58. Reynolds WM. Suicidal Ideation Questionnaire: Professional Manual. Odessa, FL: Psychological Assessment Resources; 1988.

59. Reynolds WM. Suicidal Ideation Questionnaire: Professional manual. Odessa, FL: Psychological Assessment Resources; 1988.

60. Hamer RM, Simpson PM. Last observation carried forward versus mixed models in the analysis of psychiatric clinical trials. Am J Psychiatry. 2009; 166(6): 639-41.

61. Altman, DG. Confidence intervals for the number needed to treat. BMJ. 1998; 317: 1309-1312.

62. Jo B, Ginexi E, lalongo N. Handling missing data in randomized experiments with noncompliance. Prevention Science 2010; 11: 384-396.

63. Mackinnon DP. Introduction to statistical mediation analysis. New York: Erlbaum; 2008.

64. Stafford L, Berk M. The use of statins after a cardiac intervention is associated with reduced risk of subsequent depression: proof of concept for the inflammatory and oxidative hypotheses of depression? J Clin Psychiatry 2011; 72(9): 1229-35. 
65. Therapeutic Goods Administration. Note for guidance on good clinical practice (CPMP/ICH/135/95 - Annotated with TGA comments); July 2000. Available from: https://www.tga.gov.au/sites/default/files/ich13595an.pdf.

66. National Health and Medical Research Council. The national statement on ethical conduct in human research 2007 (Updated May 2015); May 2015. Available from:

https://www.nhmrc.gov.au/_files_nhmrc/publications/attachments/e72_national_st atement_may_2015_150514_a.pdf.

67. Bortolasci CC, Vargas HO, Souza-Nogueira A, Barbosa DS, Moreira EG, Nunes SO, et al. Lowered plasma paraoxonase (PON)1 activity is a trait marker of major depression and PON1 Q192R gene polymorphism-smoking interactions differentially predict the odds of major depression and bipolar disorder. J Affect Disord 2014; 159: 23-30.

68. Newton-Howes G, Tyrer P, Johnson T, Mulder R, Kool S, Dekker J, et al. Influence of personality on the outcome of treatment in depression: A systematic review and meta-analysis. J Pers Disord 2014; 28(4): 577-93.

69. Akiskal H, Walker FR, Puzantian VR, King D, Rosenthal TL, Dranon M. Bipolar outcome in the course of depressive illness. Phenomenologic, familial, and pharmacologic predictors. J Affect Disord 1983; 5(2): 115-28.

70. Beesdo K, Höfler M, Leibenluft E, Lieb R, Bauer M, Pfennig A. Mood episodes and mood disorders: patterns of incidence and conversion in the first three decades of life. Bipolar Disord 2009; 11(6): 637-49. 
71. Fiederowicz JG, Endicott J, Leon AC, Solomon DA, Keller MB, Coryell WH. Subthreshold hypomanic symptoms in progression from unipolar major depression to bipolar disorder. Am J Psychiatry 2011; 168(1): 40-8. 
Table 1: Instruments and procedures that are implemented at each study visit.

\begin{tabular}{|c|c|c|c|c|c|c|c|}
\hline VISIT & $\begin{array}{l}0 \\
\text { Screening } \\
\text { Phase }\end{array}$ & $\begin{array}{l}1 \\
\text { Baseline }\end{array}$ & $\begin{array}{l}2 \\
\text { Phone call }\end{array}$ & $\begin{array}{l}3 \\
\text { Interim } \\
\text { assessment }\end{array}$ & $\begin{array}{l}4 \\
\text { Interim } \\
\text { assessment }\end{array}$ & $\begin{array}{l}5 \\
\text { Primary } \\
\text { Endpoint }\end{array}$ & $\begin{array}{l}6 \\
\text { Follow-up } \\
\text { phone } \\
\text { interview }\end{array}$ \\
\hline WEEK & -3 (weeks) & 0 & 2 & 4 & 8 & 12 & 26 \\
\hline \multicolumn{8}{|l|}{ SCREENING AND CONSENT } \\
\hline Informed consent & $\mathrm{X}$ & & & & & & \\
\hline Inclusion/exclusion criteria & $x$ & & & & & & \\
\hline Medical history & $\mathrm{x}$ & & & & & & \\
\hline Clinical blood test & $x$ & & & & & $x$ & \\
\hline Pregnancy test (females only) † & $\mathrm{X}$ & & & & & & \\
\hline SCID-I/P & $\mathrm{X}$ & & & & & & $X \neq$ \\
\hline YMRS & $\mathrm{X}$ & & & & & $\mathrm{X}$ & \\
\hline Drug dispensation & & $x$ & & $\mathrm{X}$ & $\mathrm{X}$ & & \\
\hline \multicolumn{8}{|l|}{ SAFETY } \\
\hline Adverse events recording sheet & & & $x$ & $x$ & $x$ & $x$ & $x$ \\
\hline SIQ & & $x$ & & $x$ & $\mathrm{x}$ & $x$ & \\
\hline AUDIT & & $x$ & & $x$ & $\mathrm{x}$ & $\mathrm{x}$ & \\
\hline \multicolumn{8}{|l|}{ EFFECTIVENESS } \\
\hline MADRS & & $x$ & & $x$ & $x$ & $x$ & $x$ \\
\hline QIDS-SR & & $x$ & & $x$ & $\mathrm{x}$ & $x$ & \\
\hline GAD-7 & & $\mathrm{X}$ & & $\mathrm{X}$ & $\mathrm{X}$ & $\mathrm{X}$ & \\
\hline CGI-S & & $\mathrm{X}$ & & $\mathrm{X}$ & $\mathrm{X}$ & $\mathrm{X}$ & \\
\hline CGI-I & & & & $\mathrm{X}$ & $\mathrm{x}$ & $\mathrm{X}$ & \\
\hline PGI & & & & & & $\mathrm{x}$ & \\
\hline \multicolumn{8}{|c|}{ FUNCTIONING AND QUALITY OF LIFE } \\
\hline Q-LES-Q-SF & & $\mathrm{X}$ & & & & $\mathrm{X}$ & \\
\hline SOFAS & & $\mathrm{X}$ & & & & $x$ & $\mathrm{X}$ \\
\hline
\end{tabular}




\begin{tabular}{|c|c|c|c|c|c|c|c|}
\hline VISIT & $\begin{array}{l}0 \\
\text { Screening } \\
\text { Phase }\end{array}$ & $\begin{array}{l}1 \\
\text { Baseline }\end{array}$ & $\begin{array}{l}2 \\
\text { Phone call }\end{array}$ & $\begin{array}{l}3 \\
\text { Interim } \\
\text { assessment }\end{array}$ & $\begin{array}{l}4 \\
\text { Interim } \\
\text { assessment }\end{array}$ & $\begin{array}{l}5 \\
\text { Primary } \\
\text { Endpoint }\end{array}$ & $\begin{array}{l}6 \\
\text { Follow-up } \\
\text { phone } \\
\text { interview }\end{array}$ \\
\hline WEEK & -3 (weeks) & 0 & 2 & 4 & 8 & 12 & 26 \\
\hline SAS-SR - 64 & & $\mathrm{x}$ & & & & $\mathrm{x}$ & \\
\hline $\begin{array}{ll}\text { ASSESSMENT OF } & \text { PREDICTORS, } \\
\text { MODERATORS AND MEDIATORS }\end{array}$ & & & & & & & \\
\hline DAPP-BQ & & & & $\mathrm{X}$ & & & \\
\hline NPOQ & & $\mathrm{x}$ & & & & $x$ & \\
\hline BSDS & & & & $x$ & & & \\
\hline Bipolarity Index & & & & $\mathrm{x}$ & & & \\
\hline - $\quad$ Affective Disorders Evaluation & & & & $x$ & & & \\
\hline - $\quad$ Family History Questionnaire & & & & & $x$ & & \\
\hline $\begin{array}{l}\text { - Antidepressant associated mood } \\
\text { changes }\end{array}$ & & & & & & $\mathrm{X}$ & \\
\hline - $\quad$ Subthreshold mania questions & & $x$ & & & & & \\
\hline - OTHER & & & & & & & \\
\hline Demographics & & $x$ & & & & & \\
\hline Psychiatric and family history & & $x$ & & & $x$ & & \\
\hline Concomitant medication & & $\mathrm{x}$ & & $\mathrm{X}$ & $x$ & $\mathrm{X}$ & $\mathrm{X}$ \\
\hline Research blood sample - Biomarkers & & $\mathrm{X}$ & & & & $\mathrm{X}$ & \\
\hline
\end{tabular}

+ If participant is not sexually active or the treating clinician feels it is not warranted, this is not compulsory.

$\ddagger$ Only the mood modules from the SCID are conducted at week 26 as part of the bipolarity index. 
Table Legend:

SCID I/P (Structured Clinical Interview for DSM-IV Axis I Disorders); YMRS (Young Mania Rating Scale); SIQ (Suicidal Ideation Questionnaire); AUDIT (Alcohol Use Disorders Identification Test); MADRS (Montgomery Åsberg Depression Rating Scale); QIDS-SR (Quick Inventory of Depressive Symptamology); GAD-7 (Generalized Anxiety Disorder 7-item scale); CGI-S (Clinical Global Impression-Severity scale); CGI-I (Clinical Global Impression-Improvement scale); PGI (Patient Global Impression Improvement); Q-LES-Q-SF (Quality of life Enjoyment and Satisfaction Questionnaire - Short Form); SOFAS (Social and Occupational Functioning Scale), SAS-SR-64 (Social Adjustment Scale - Self Report); DAPP-BQ (Dimensional Assessment of Personality Pathology - Basic Questionnaire); NPOQ (Negative Problem Orientation Questionnaire); BSDS (Bipolar Spectrum Diagnostic Scale). 
Figure 1 - Flowchart of study design. 


\section{University Library}

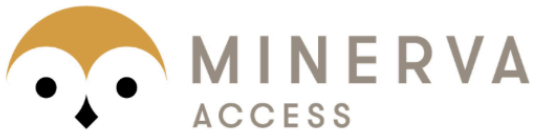

A gateway to Melbourne's research publications

Minerva Access is the Institutional Repository of The University of Melbourne

\section{Author/s:}

Quinn, AL;Dean, OM;Davey, CG;Kerr, M;Harrigan, SM;Cotton, SM;Chanen, AM;Dodd, S;Ratheesh, A;Amminger, GP;Phelan, M;Williams, A;Mackinnon, A;Giorlando, F;Baird, S;Rice, S;O'Shea, M;Schaefer, MR;Mullen, E;Hetrick, S;McGorry, P;Berk, M

Title:

Youth Depression Alleviation-Augmentation with an anti-inflammatory agent (YoDA-A): protocol and rationale for a placebo-controlled randomized trial of rosuvastatin and aspirin

Date:

2018-02-01

\section{Citation:}

Quinn, A. L., Dean, O. M., Davey, C. G., Kerr, M., Harrigan, S. M., Cotton, S. M., Chanen, A. M., Dodd, S., Ratheesh, A., Amminger, G. P., Phelan, M., Williams, A., Mackinnon, A., Giorlando, F., Baird, S., Rice, S., O'Shea, M., Schaefer, M. R., Mullen, E. ,... Berk, M. (2018). Youth Depression Alleviation-Augmentation with an anti-inflammatory agent (YoDA-A): protocol and rationale for a placebo-controlled randomized trial of rosuvastatin and aspirin. EARLY INTERVENTION IN PSYCHIATRY, 12 (1), pp.45-54. https://doi.org/10.1111/eip.12280.

Persistent Link:

http://hdl.handle.net/11343/59191 